\title{
SUCESSO EM PROJETOS PÚBLICOS: UMA ANÁLISE BIBLIOMÉTRICA
}

\author{
SUCCESS IN PUBLIC PROJECTS: A BIBLIOMETRIC ANALYSIS
}

\author{
Danillo Guimarães Rios \\ Graduado em Administração \\ Universidade Federal do Cariri - UFCA \\ Juazeiro do Norte, Ceará - Brasil \\ dangrios@gmail.com \\ Jeniffer de Nadae \\ Doutora em Engenharia de Produção \\ Universidade Federal do Cariri - UFCA \\ Juazeiro do Norte, Ceará - Brasil \\ jnadae@gmail.com \\ Rafael Rossi Buzzetto \\ Mestrando em Engenharia de Produção \\ Escola Politécnica da Universidade de São Paulo - POLI/USP \\ São Paulo, São Paulo - Brasil \\ rafael.buzzetto@hotmail.com
}

Resumo

Por meio de uma análise bibliométrica, esta pesquisa mapeia a produção científica sobre sucesso em projetos públicos em periódicos disponibilizados na base Web of Science, abrangendo todas as publicações disponibilizadas até o fim de maio de 2019. A amostra compreendeu 248 artigos publicados em 154 periódicos internacionais. Os resultados mostram que a atenção ao tema vem crescendo consideravelmente desde 2013. Porém, a relevância brasileira é muito baixa, se comparada a outros países como Estados Unidos, China, Inglaterra e Austrália, que juntos representam quase 50\% da amostra, enquanto o Brasil representa menos de 1\%, o que traz um alerta sobre a necessidade da pesquisa acerca do tema. Após análise, os Fatores Críticos de Sucesso (FCS) foram classificados de acordo com Shenhar, Dvir e Levy (2001), sendo os fatores 'preparação para o futuro' (39\%) e 'sucesso do negócio' (27\%) os que apareceram com maior frequência. Para a literatura, esta pesquisa contribui com um framework acerca do tema. Para gestores de projetos, esta pesquisa contribui com uma lista dos fatores críticos mais apontados pela literatura, o que pode auxiliá-los a aumentar os índices de sucesso em seus projetos públicos.

Palavras-chave: Sucesso em Projetos Públicos. Análise Bibliométrica. Fatores Críticos de Sucesso.

\begin{abstract}
Through a bibliometric analysis, this research maps the scientific production on Success in Public Projects in journals made available on the Web of Science database, covering all publications made available until the end of May 2019. The sample comprised 248 articles published in 154 international journals. The results show that attention to the topic has grown considerably since 2013. However, Brazilian relevance is very low, when compared to countries such as the United States, China, England and Australia, which together represent almost $50 \%$ of the sample, while Brazil represents less than 1\%, which brings an alert of the need for research on the topic. The papers were analyzed and the Critical Success Factors were classified according to Shenhar, Dvir \& Levy (2001), being the factors: Preparation for the Future (39\%) and Business Success (27\%) the ones that appeared more frequently. For the literature, this research contributes to a framework on the theme. For project managers, this research contributes to a list of the critical factors most mentioned in the literature, which can help them to increase the success rates in their public projects.
\end{abstract}

Keywords: Success in Public Projects. Bibliometric Analysis. Critical Success Factors. 


\section{Cite como - American Psychological Association (APA)}

Rios, D. G., Nadae, J. de, Buzzetto, R. R., \& Freitas, S. de L. T. U. (2020, set./dez.). Sucesso em projetos públicos: uma análise bibliométrica. Revista de Gestao e Projetos (GeP), 11(3), 117-135.

https://doi.org/10.5585/gep.v11i3.18514.

\section{Introdução}

A competitividade entre as organizações empresariais, sejam elas do setor público ou privado, se encontram em um estado de crescente intensidade, na qual todas buscam ser dinâmicas e resilientes, sendo capazes de se reestruturar rapidamente, conforme as necessidades do mercado. Diante dessa situação, gestores tem investido em melhores formações e conhecimento para aumentar suas competências (Kerzner, 2010).

As empresas, sejam elas públicas ou privadas, buscam continuamente melhorar a gestão dos seus projetos, definidos como um empreendimento com um objetivo bem definido, que consome recursos e opera com prazos pré-estabelecidos (Kerzner, 2010). Patah (2012) explica que a gestão de projetos pode ser visualizada como processos estruturados, aplicados sequencialmente, repetidamente, continuamente e, quando utilizados de forma gradual por uma organização, permite a aproximação da institucionalização de práticas padronizadas. Estas práticas padronizadas têm a função de aumentar a assertividade nos resultados dos projetos.

É muito comum associar a figura do gestor de projetos ao ambiente privado. Entretanto, isso também se aplica às instituições públicas, as quais não visam lucro (Conde \& Araújo-Jorge, 2003). Neste caso, o Estado pode encaminhar recursos por meio dos projetos públicos, tendo como principal intuito o atendimento das necessidades e interesses da comunidade e do grande coletivo da sociedade (Pestana \& Valente, 2010).

Mesmo não focando em atividades que tragam lucro à instituição, os projetos públicos precisam utilizar o dinheiro recebido de maneira assertiva, aumentando a eficácia nos resultados alcançados com os projetos. Para tanto, faz-se necessária a implantação da atividade de gestão de projetos, que tem por objetivo a realização da gestão dos recursos adquiridos de maneira eficiente (Link, Silva, Barichello, \& Magro, 2020).

A questão do sucesso de projetos é mais comumente associada às características estruturais das organizações e do projeto, o que inclui variáveis como a formação da equipe, o perfil do gerente do projeto, dentre outros (Pinto, 2002). Apesar disso, podemos inferir que, em instituições públicas, a importância da gestão de projetos é inquestionável, a qual age voltando-se, não exclusivamente ao lado estrutural, mas também ao lado humano (Da Costa, 2002).

Segundo De Farias Filho (2019), o sucesso em um projeto é definido pelo alcance 
do seu objetivo final e não apenas por sua entrega no prazo, orçamento e escopo previamente definidos. Segundo o mesmo autor, há projetos muito bem gerenciados quanto aos prazos, orçamentos e escopo, mas quando aplicados se tornam um fracasso, enquanto outros, que sofrem problemas de prazo, orçamento ou até escopo, acabam por se tornar um grande sucesso quando aplicados (De Farias Filho, 2019). Isso demonstra que o sucesso dos projetos está totalmente alinhado a estratégia da organização e com o objetivo previamente definido sobre a aplicabilidade do seu resultado. Corroborando com esta afirmação, Russo e Silva (2019) ressaltam a necessidade da organização equalizar as visões de todos os stakeholders envolvidos quanto ao real significado do sucesso do projeto.

Diante disso, é necessário estabelecer características, variáveis ou critérios de sucesso que auxiliem as empresas a determinar se um projeto teve sucesso ou fracasso, isso pode ser definido como Fator Crítico de Sucesso (FCS). Turner (1996) define FCS de projetos como os elementos do projeto, ou de sua gestão, que podem ser influenciados para aumentar a chance de alcançar um resultado bem-sucedido.

Os FCS podem ser considerados uma metodologia utilizada como meio de identificar as áreas de atividade mais importantes e essenciais para a realização de um projeto com sucesso (Azimi \& Manesh, 2012).

A literatura apresenta diversas definições de FCS em projetos. Bullen e Rockart (1981) definem FCS como um número restringido de áreas, em que resultados satisfatórios garantirão um desempenho competitivo de sucesso para o indivíduo, departamento ou organização. Bruno e Leidecker (1984) consideram determinadas características, condições ou variáveis que, quando devidamente apoiadas, conduzidas ou administradas, podem ter um impacto importante no sucesso e na competitividade de uma empresa. Forster e Rockart (1989) consideram o foco em um número reduzido de problemas críticos ou oportunidades. Para Hart (1993) é a tendência à inovação. Kleinschmidt e Cooper (1991) definem como produtos de baixa ou alta inovação. Shenhar, Dvir e Levy (2001) consideram quatro fatores: eficiência do projeto, sucesso do negócio, impacto no consumidor, e preparação para o futuro. Procedimentos de pré-desenvolvimento, a justa e precisa avaliação do potencial de mercado, são os FCS apresentados por Toledo, Silva, Mendes e Jugend (2008). Poolton e Barclay (1998) identificam os fatores críticos em estratégicos e táticos. De acordo com Buchanan (2008), os fatores críticos podem ser divididos em medidas preditivas e medidas corretoras.

Este trabalho tem como objetivo analisar a produção científica internacional que aborda o tema "sucesso em projetos públicos" e seus fatores críticos de sucesso, por meio da análise bibliométrica - um estudo quantitativo das publicações encontrados na base de dados Web of Science.

Diante deste objetivo, o artigo está dividido em cinco seções. Além da parte 
introdutória, a segunda seção aborda a revisão da literatura; a terceira seção engloba os métodos de pesquisa utilizados; a quarta seção apresenta os resultados encontrados; a quinta e última seção apresenta as considerações finais da pesquisa.

\section{Referencial teórico}

\subsection{Fatores Críticos de Sucesso em Projetos}

Um projeto é um empreendimento único, com começo e fim já definidos, que utiliza recursos circunscritos e é conduzido por pessoas, aspirando alcançar metas e objetivos já definidos, estabelecidos dentro de especificações de prazo, custo e qualidade (PMI, 2000).

Keeling (2017) explica que o gerenciamento de projetos não é algo novo, afinal as pirâmides foram projetos. Porém, a profissionalização do gerenciamento de projetos e a criação de uma área do conhecimento específica é datada no século XX. No século XXI o trinômio estratégiaprojetos-qualidade se torna um diferencial competitivo e as organizações precisam visualizar aonde querem chegar.

Segundo Duffy (2006), a gestão de projetos é algo muito complexo e preenchido por contradições, uma vez que, ao mesmo tempo em que se faz necessário preparar um plano abrangente e bem discriminado, também é necessário lidar com o improvável, ou seja, embora o foco se mantém no objetivo final, é necessário adotar uma visão sistêmica para manter o projeto alinhado, enquanto possíveis problemas são resolvidos.

$$
\text { Para Kerzner (2011) o }
$$

gerenciamento de projetos compreende o controle, o planejamento e a direção dos recursos da organização para um dado objetivo, normalmente de curto prazo e que fora estabelecido para concluir metas e objetivos específicos.

De acordo com BSI (2000), é responsabilidade da gestão de projetos o monitoramento, o planejamento e o controle de todos os aspectos de um projeto, além da motivação de todos os envolvidos, cujo propósito é alcançar os objetivos dentro do prazo, orçamento, qualidade e performance desejada.

No ambiente empresarial, o termo 'Fatores Críticos de Sucesso' (FCS), é definido como um número restringido de áreas em que os resultados satisfatórios garantirão um desempenho competitivo de sucesso para o indivíduo, departamento ou organização (Bullen \& Rockart, 1981). Na mesma linha, os autores Bruno e Leidecker (1984) definem FCS como determinadas características, condições ou variáveis que, quando devidamente apoiadas, conduzidas ou administradas, podem ter um impacto 
importante no sucesso e na competitividade de uma empresa.

A partir de Forster e Rockart (1989), é possível inferir que o conceito de FCS é utilizado há um longo período: Aristóteles inteirou a ideia de que os líderes deveriam conceber poucos e também simples objetivos para suas organizações e ressaltou que as organizações que assim o fizeram obtiveram resultados superiores, frente as que não o fizeram. Por esse mesmo aspecto, o Barão Von Clausewitz, redigindo ao Staff sobre os princípios da guerra, estabeleceu um deles como sendo "a concentração de forças", a partir do que ele infere que os "maus generais" dispersaram suas forças pelo campo de batalha, ao mesmo tempo em que os "bons generais", de forma a assegurar a vitória, concentravam suas forças em poucas batalhas, porém críticas, que precisavam ser vencidas. Entretanto, manter $\mathrm{o}$ foco somente em importantes batalhas, traçadas na execução de projetos, não é suficiente para levar a empresa à prosperidade no mercado.

Segundo Hart (1993), há uma forte relação dessa prosperidade ligada às empresas com tendência de inovação. Porém, não há concordância quanto a afinidade entre o grau de inovação do produto e seu sucesso no mercado (Garcia \& Calantone, 2002). Ainda sobre uma possível tendência de inovação, Kleinschmidt e Cooper (1991) reiteram que os produtos altamente inovadores e os de baixo grau de inovação são mais bemsucedidos que produtos de inovação moderada.

Já segundo Shenhar, Dvir e Levi (2001), são notórios os seguintes fatores de sucesso: a eficiência do projeto, o sucesso do negócio, o impacto no consumidor e a preparação para o futuro - que engloba o cumprimento de prazos, a satisfação do cliente, a geração de receita e o desenvolvimento de tecnologia para o futuro, dentre outros. Toledo, Silva, Mendes e Jugend (2008), acrescentam como FCS a importância dos procedimentos de pré-desenvolvimento, a justa e precisa avaliação do potencial de mercado e o desenvolvimento de capacidades gerenciais e de relacionamento do gerente ou líder de projeto.

Cada empresa, seja ela de grande, médio ou pequeno porte, possui seus próprios FCS, sendo a identificação desses extremamente importante para conseguir sucesso nos projetos (Quintella, Rocha, \& Alves, 2005). Segundo Rabechini Junior e Carvalho (2009), a grande quantidade de projetos nas organizações é o que estimula a busca pelos FCS. Por outro lado, apontam os autores, ainda é baixo o consenso sobre 
as variáveis que levam ao sucesso de um projeto.

Poolton e Barclay (1998), discordam que os FCS são de fato relevantes. Segundo os autores, a adoção de alguns dos FCS não tem obtido a efetividade desejada, o que acaba por resultar em desprestígio quanto ao seu potencial. Sugerem, ainda, que haja uma separação dos fatores críticos em 'estratégicos' e 'táticos'. A competência dos fatores táticos inclui a efetiva comunicação interna e externa, o contentamento do cliente, a qualidade no gerenciamento e na execução de tarefas, sendo essa competência dependente da construção de um ambiente adequado, que é possível com a correta utilização de fatores estratégicos. Quanto aos fatores estratégicos, os autores atribuem o apoio da alta administração, a visão estratégica e direcionada para a inovação, o compromisso com projetos mais relevantes, a flexibilidade, a análise do risco e o incentivo à cultura empreendedora.
A Tabela 1 sintetiza a definição de FCS abordados no referencial teórico. 
Tabela 1 - Fatores Críticos de Sucesso

\begin{tabular}{|c|c|}
\hline Fatores Críticos de Sucesso & Autores (ano) \\
\hline $\begin{array}{l}\text { Número restringido de áreas em que os resultados } \\
\text { satisfatórios garantirão um desempenho competitivo } \\
\text { de sucesso para o indivíduo, departamento ou } \\
\text { organização. }\end{array}$ & Bullen \& Rockart (1981) \\
\hline $\begin{array}{l}\text { Determinadas características, condições ou } \\
\text { variáveis que, quando devidamente apoiadas, } \\
\text { conduzidas ou administradas, podem ter um } \\
\text { impacto importante no sucesso e na competitividade } \\
\text { de uma empresa. }\end{array}$ & Bruno \& Leidecker (1984) \\
\hline $\begin{array}{l}\text { Foco em um número reduzido de problemas críticos } \\
\text { ou oportunidades. }\end{array}$ & Forster \& Rockart (1989) \\
\hline Produtos de baixa ou alta inovação & Kleinschmidt \& Cooper (1991) \\
\hline Tendência de inovação & Hart (1993) \\
\hline Fatores críticos divididos em estratégicos e táticos & Poolton \& Barclay (1998) \\
\hline $\begin{array}{l}\text { Eficiência do projeto; } \\
\text { Sucesso do negócio; } \\
\text { Impacto no consumidor; } \\
\text { Preparação para o futuro. }\end{array}$ & Shenhar, Dvir \& Levy (2001) \\
\hline $\begin{array}{l}\text { Procedimentos de pré-desenvolvimento, a justa e } \\
\text { precisa avaliação do potencial de mercado. }\end{array}$ & Toledo, Silva, Mendes \& Jugend (2008) \\
\hline $\begin{array}{l}\text { Fatores críticos divididos em medidas preditivas e } \\
\text { medidas corretoras. }\end{array}$ & Buchanan (2008) \\
\hline
\end{tabular}

Fonte: Autores.

A avaliação do sucesso de um projeto é mais complexa do que simplesmente analisar o atendimento dos requisitos a partir do planejamento realizado sob restrições de escopo, prazo e custo (Shenrar \& Dvir, 2007). Esse tipo de abordagem não é mais suficiente para confirmar tal análise (Shenrar, Dvir, Levy \& Maltz, 2001).

Diferentes definições de FCS são apresentadas na literatura ao longo dos anos, como mostra o Quadro 1. Este estudo analisará os artigos selecionados na base da Web of
Science a partir do conceito apresentado por Shenhar, Dvir e Levy (2001), por conter mais variáveis e por ser mais utilizada na gestão de projetos. Na próxima seção, são exibidos os procedimentos metodológicos e as etapas para a construção deste estudo.

\section{Metodologia}

Este trabalho utilizou como método de pesquisa a análise bibliométrica, termo que foi criado em 1969, sendo considerada uma 
disciplina de alcance multidisciplinar, que analisa um dos aspectos mais relevantes e objetivos desta comunidade, a comunidade impressa (Spinak, 1996 apud Vanti, 2002).

Para Chueke (2015) a análise bibliométrica relembra os primórdios da humanidade, quando Aristóteles propunha que as ideias são criadas a partir da contradição e contraposição de ideias anteriores, partindo da premissa de que todos devem saber o que todos falam a respeito de um tema para evoluirmos em conhecimento.

A base de dados utilizada para este estudo foi a ISI Web of Science. Esta base tem grande relevância no meio acadêmico, assim como opções de tratamento de dados diferenciais (Franco, Hirama, \& Carvalho, 2018).

A busca foi estruturada considerando as palavras-chave: "success" and "project" "and "public sector*". A busca trouxe um total de 302 publicações até o fim do mês de maio de 2019, data em que a pesquisa foi realizada. Aplicou-se como primeiro filtro o tipo de documento, selecionando apenas 'artigos': a busca passou a contar com 288 publicações. O terceiro filtro selecionou o idioma dos artigos, sendo a 'língua inglesa' escolhida com intuito de facilitar a leitura para uma análise mais acurada das publicações, o que diminuiu a amostra para 267 artigos. Deste total, apenas 248 artigos estavam disponíveis para download, fechando então a amostra que compõe esta pesquisa.
Os 248 artigos da amostra foram divididos entre os autores, que prosseguiram com a leitura para análise da definição de sucesso utilizada em cada publicação, os métodos de pesquisa aplicados, o objetivo da pesquisa e principais resultados obtidos pelos autores. Foi realizada, também uma análise mais detalhada dos artigos com maior quantidade de citações (outliers), apresentados na próxima seção.

Os resultados desta pesquisa, buscam descrever a evolução da produção científica a respeito da temática de 'Sucesso em Projetos', quando relacionado ao setor público.

\section{Análise dos resultados}

Com base na amostra selecionada, foi realizada uma síntese com as informações extraídas e as principais considerações levantadas a respeito das publicações entre 1992 e maio de 2019, analisando assim os últimos 27 anos de produção.

Sobre a quantidade de artigos que abordam o tema 'sucesso em projetos públicos', a figura 1 mostra que o tema vem sendo estudado desde o ano de 1992. Entretanto, a quantidade de publicações só passou a ser relevante a partir do ano de 2007, quando as produções pulam do máximo anual de 5 para 12 e, a partir de 2013, é percebida uma relevância mais predominante, quando o número de publicações permanecem altos em comparação aos anos anteriores, com destaque ao ano de 2018 com 38 publicações que, sozinho, teve mais publicações que os 15 anos iniciais. 
Além do crescimento do número de publicações, é percebido que nos anos de 1996 e 2006 não houve publicações a respeito do tema. Os primeiros artigos datam de 1992. O artigo intitulado Technology-transfer to the private-sector - a field-study of manufacturer buying behavior, de Large \& Barclay (1992), aborda a transferência de tecnologia do setor público para o privado, acompanhando o processo de compra dessas tecnologias. Já a publicação de Considine (1992), intitulada
Alternatives to hierarchy - the role and performance of lateral structures inside bureaucracy, aborda alternativas para hierarquia, comparando as estruturas laterais com a hierarquia tradicional. Isso demonstra uma tendência de que os fatores críticos que impactam o sucesso em projetos públicos são percebidos pelas organizações de formas diferente, tendendo a motivação guiada pela estratégia adotada.

Figura 1 - Evolução histórica das publicações relacionadas ao tema da pesquisa

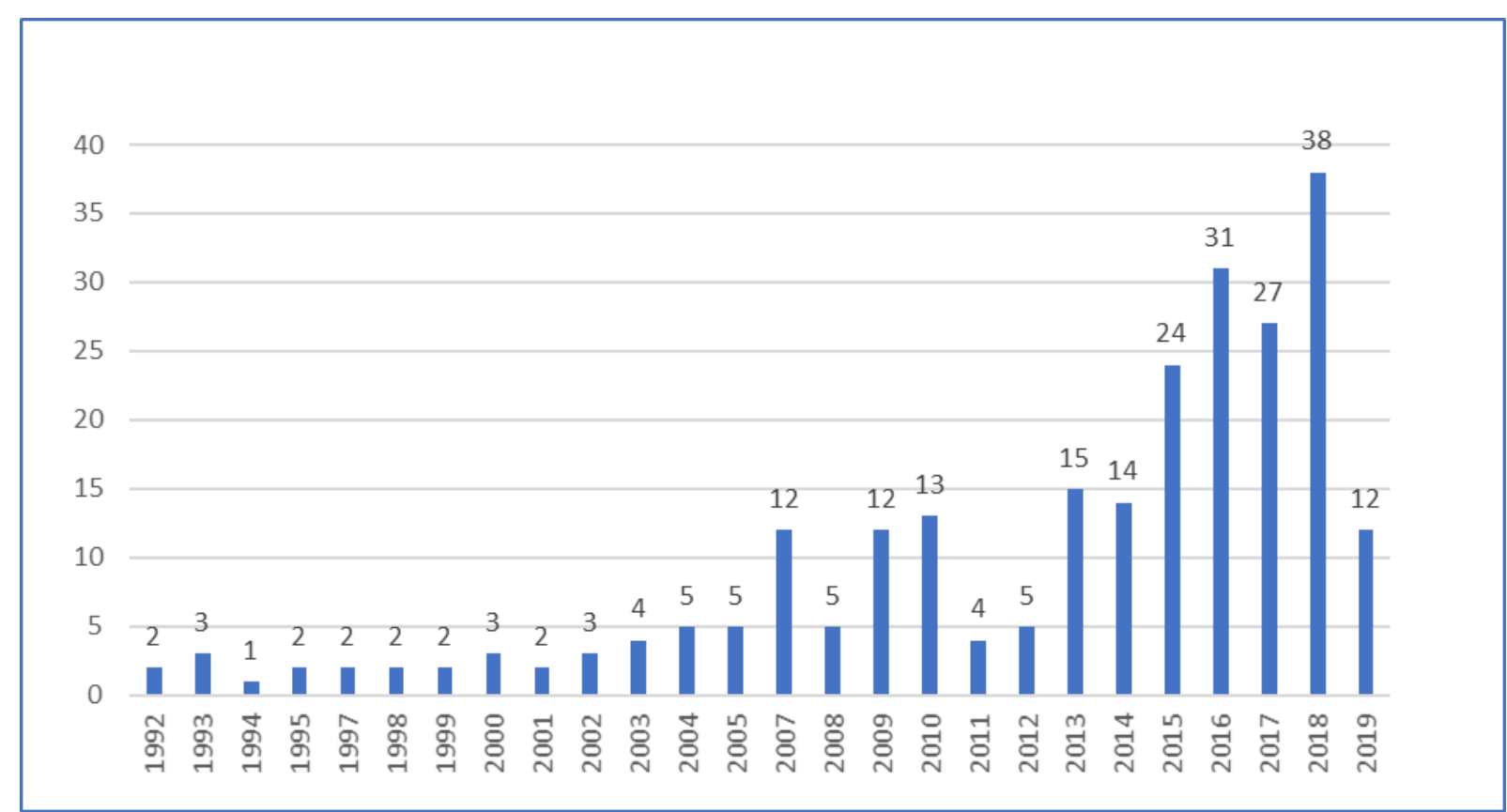

Fonte: Autores.

Em 2016, as publicações indicam que os FCS que podem influenciar os projetos públicos são o poder de negociação e o balanceamento das metas com os participantes; o tempo de implementação do projeto; a estrutura de decisão e governança; a correta alocação dos riscos; a metodologia de gestão do projeto; os processos de avaliação do processo; a inteligência emocional dos gerentes de projeto; o desempenho dos processos de licitações; o compartilhamento do conhecimento e o engajamento dos membros da equipe; as estratégias de investimentos utilizados; a maturidade do país; o treinamento da equipe e seu trabalho em conjunto; e, finalmente, a entrega de objetivos estratégicos. 
Os artigos do ano de 2018 tratam da avaliação e comparação de estruturas de contratos, criando solução ganha-ganha, apresentam como FCS o cumprimento dos objetivos exigidos no contrato; a correta identificação e alocação dos riscos; os incentivos fiscais; a política do país; o envolvimento e colaboração dos stakeholders; a estabilidade organizacional; a gestão adequada; o desenvolvimento de competências transversais; o aumento do nível de qualificação da equipe; a forte capacidade financeira e fontes externas de financiamento; o atendimento às restrições orçamentárias; a entrega no prazo e objetivos alcançados; bons desempenhos individuais; metas e objetivos alcançados; compromisso e apoio do governo; forte apoio da comunidade; integração do fluxo de trabalho e dos processos; comunicação constante; escopo bem definido; evitar conflitos entre os parceiros; e o comprometimento entre os stakeholders.

As publicações do ano de 2019, de maneira geral, analisam o gerenciamento inadequado de informações e de como minimizar os efeitos negativos da má gestão da informação em projetos; expõem ainda que os FCS podem ser influenciados pela estrutura organizacional, políticas, metas agressivas, metas compartilhadas, aplicação do conhecimento, boa capacidade de lidar com o governo, bom relacionamento entre as partes, captação de recursos, governança eficaz dos projetos e correta identificação e alocação dos riscos.

Baseado na análise quantitativa de países que abordam sucesso em projetos públicos, há um registro de 50 países nos quais pelo menos um artigo foi produzido, conforme mostra a figura 2 .

Figura 2 - Publicações por país

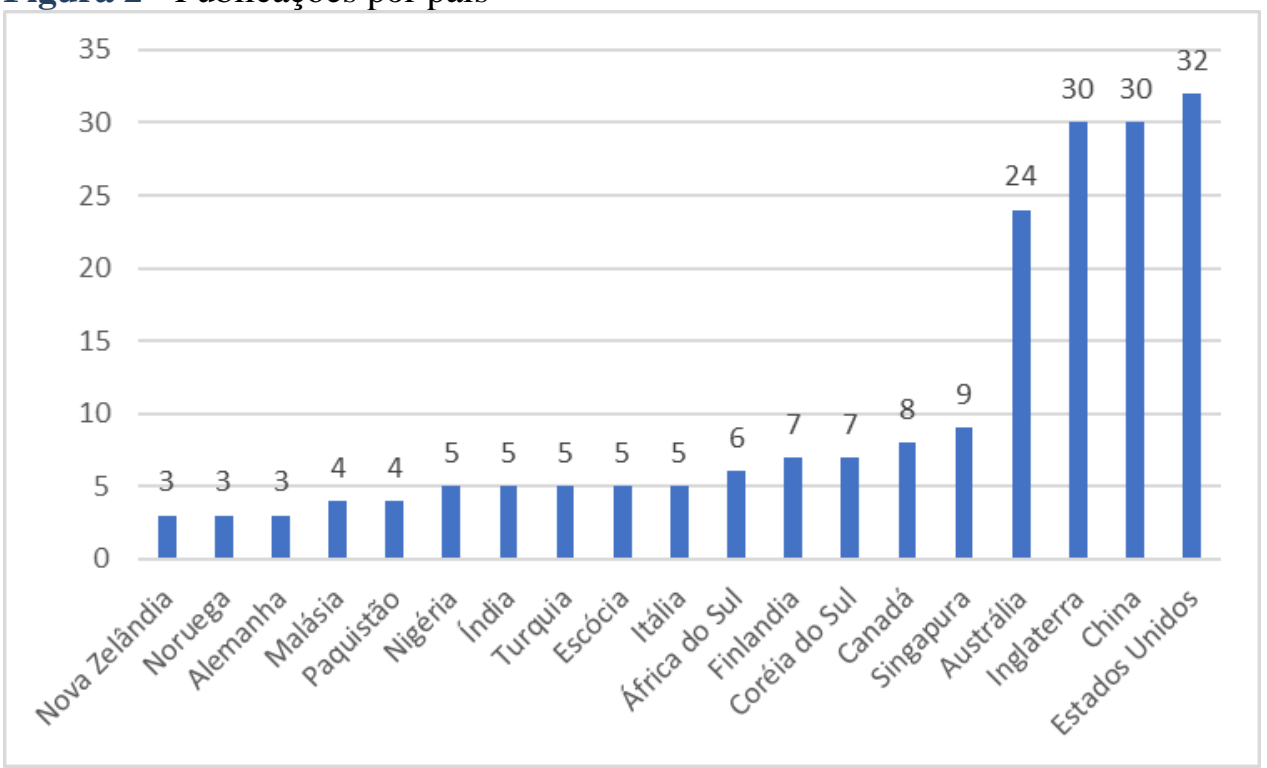

Fonte: Autores. 
Nota-se que quatro países juntos introduzindo a sustentabilidade no representam, aproximadamente, $50 \%$ do total gerenciamento de projetos, investigando de publicações: Estados Unidos, China, também como essa iniciativa pode impactar no Inglaterra e Austrália. O Brasil produziu apenas sucesso do projeto. Neste caso, apresentam dois artigos, representando menos de $1 \%$ da como FCS a importância de incentivos fiscais e amostra. Os pesquisadores brasileiros têm a necessidade de práticas sustentáveis para o analisado o processo de gestão territorial sucesso dos projetos públicos. através da implementação de um projeto de A tabela 2 sintetiza as principais investimento estrangeiro em um país características dos trabalhos mais citados da emergente, e como as empresas estão amostra: os artigos com mais de 30 citações. 
Tabela 2 - Principais características dos trabalhos com 33 ou mais citações

\begin{tabular}{|c|c|c|c|c|c|c|}
\hline Autor & Título & Citações & Ano & Método & FCS & Objetivo \\
\hline $\begin{array}{l}\text { Briedenhann, J; } \\
\text { Wickens, E }\end{array}$ & $\begin{array}{l}\text { Tourism routes as a tool } \\
\text { for the economic } \\
\text { development of rural } \\
\text { areas - vibrant hope or } \\
\text { impossible dream? }\end{array}$ & 249 & 2004 & Questionário & $\begin{array}{l}\text { Vozes da comunidade } \\
\text { ouvidas }\end{array}$ & $\begin{array}{l}\text { Discutir o desenvolvimento de } \\
\text { rotas de turismo rural na África } \\
\text { do Sul e destacar os fatores } \\
\text { críticos para o seu sucesso }\end{array}$ \\
\hline Bannerman, PL & $\begin{array}{l}\text { Risk and risk } \\
\text { management in } \\
\text { software projects: A } \\
\text { reassessment }\end{array}$ & 125 & 2008 & Revisão da literatura & Controle do risco & $\begin{array}{l}\text { Reconsiderar o gerenciamento de } \\
\text { riscos na literatura e na prática }\end{array}$ \\
\hline $\begin{array}{l}\text { Chan, APC; Ho, DCK; } \\
\text { Tam, CM }\end{array}$ & $\begin{array}{l}\text { Design and build } \\
\text { project success factors: } \\
\text { Multivariate analysis }\end{array}$ & 116 & 2001 & Survey & $\begin{array}{l}\text { Rápida resolução de } \\
\text { conflitos }\end{array}$ & $\begin{array}{l}\text { Identificar os FCS em projetos de } \\
\text { design e construção e examinar a } \\
\text { importância desses fatores no } \\
\text { resultado do projeto }\end{array}$ \\
\hline $\begin{array}{l}\text { Songer, AD; Molenaar, } \\
\text { KR }\end{array}$ & $\begin{array}{l}\text { Project characteristics } \\
\text { for successful public- } \\
\text { sector design-build }\end{array}$ & 108 & 1997 & Entrevista & $\begin{array}{l}\text { Entender as } \\
\text { características } \\
\text { importantes do projeto }\end{array}$ & $\begin{array}{l}\text { Entender quais características dos } \\
\text { projetos são críticas para os } \\
\text { sucessos para melhorar a } \\
\text { implementação do órgão público. }\end{array}$ \\
\hline $\begin{array}{l}\text { Gil-Garcia, JR; } \\
\text { Chengalur-Smith, I; } \\
\text { Duchessi, P }\end{array}$ & $\begin{array}{l}\text { Collaborative e- } \\
\text { Government: } \\
\text { impediments and } \\
\text { benefits of information- } \\
\text { sharing projects in the } \\
\text { public sector }\end{array}$ & 107 & 2007 & $\begin{array}{l}\text { Análise de dados } \\
\text { secundários }\end{array}$ & $\begin{array}{l}\text { Compartilhamento de } \\
\text { informações }\end{array}$ & $\begin{array}{l}\text { Revelar como alguns } \\
\text { impedimentos gerenciais e } \\
\text { culturais limitam as percepções } \\
\text { de benefícios esperados. }\end{array}$ \\
\hline $\begin{array}{l}\text { Molenaar, KR; Songer, } \\
\text { AD }\end{array}$ & $\begin{array}{l}\text { Model for public sector } \\
\text { design-build project } \\
\text { selection }\end{array}$ & 98 & 1998 & Revisão da literatura & $\begin{array}{l}\text { Compreensão de todas } \\
\text { as etapas do projeto e } \\
\text { aplicá-las corretamente }\end{array}$ & $\begin{array}{l}\text { Identificar quais características } \\
\text { do projeto produzem um maior } \\
\text { potencial de sucesso usando } \\
\text { design-build. }\end{array}$ \\
\hline $\begin{array}{l}\text { Wedding, GC; } \\
\text { Crawford-Brown, D }\end{array}$ & $\begin{array}{l}\text { Measuring site-level } \\
\text { success in brownfield } \\
\text { redevelopments: A } \\
\text { focus on sustainability } \\
\text { and green building }\end{array}$ & 95 & 2007 & $\begin{array}{l}\text { Entrevista e revisão da } \\
\text { literatura }\end{array}$ & Sustentabilidade & $\begin{array}{l}\text { Caracterizar e quantificar o } \\
\text { sucesso em revitalização de áreas } \\
\text { industriais abandonadas. }\end{array}$ \\
\hline
\end{tabular}




\begin{tabular}{|c|c|c|c|c|c|c|}
\hline Autor & Título & Citações & Ano & Método & FCS & Objetivo \\
\hline $\begin{array}{l}\text { Hwang, BG; Zhao, XB; } \\
\text { Gay, MJS }\end{array}$ & $\begin{array}{l}\text { Public private } \\
\text { partnership projects in } \\
\text { Singapore: Factors, } \\
\text { critical risks and } \\
\text { preferred risk allocation } \\
\text { from the perspective of } \\
\text { contractors }\end{array}$ & 93 & 2013 & Survey & Avaliação dos Riscos & $\begin{array}{l}\text { Examinar os FCS, bem como a } \\
\text { importância relativa de fatores } \\
\text { positivos e negativos } \\
\text { influenciarem a atividade dos } \\
\text { projetos de parceria público- } \\
\text { privada. }\end{array}$ \\
\hline $\begin{array}{l}\text { Chan, APC; Yeung, } \\
\text { JFY; Yu, CCP; Wang, } \\
\text { SQ; Ke, YJ }\end{array}$ & $\begin{array}{l}\text { Empirical Study of } \\
\text { Risk Assessment and } \\
\text { Allocation of Public- } \\
\text { Private Partnership } \\
\text { Projects in China } \\
\end{array}$ & 92 & 2011 & Questionário & Avaliação dos Riscos & $\begin{array}{l}\text { Avaliação de riscos e alocação de } \\
\text { projetos de parceria público- } \\
\text { privada na China. }\end{array}$ \\
\hline Goldfinch, S & $\begin{array}{l}\text { Pessimism, computer } \\
\text { failure, and information } \\
\text { systems development in } \\
\text { the public sector }\end{array}$ & 91 & 2007 & $\begin{array}{l}\text { Análise de dados } \\
\text { secundários }\end{array}$ & Orçamento do projeto & $\begin{array}{l}\text { Descrever os problemas de } \\
\text { entusiasmo e os problemas de } \\
\text { controle que tornam o fracasso de } \\
\text { grandes desenvolvimentos quase } \\
\text { inevitável. }\end{array}$ \\
\hline Heeks, R; Stanforth, C & $\begin{array}{l}\text { Understanding e- } \\
\text { Government project } \\
\text { trajectories from an } \\
\text { actor-network } \\
\text { perspective }\end{array}$ & 76 & 2007 & Estudo de caso & Redes locais & $\begin{array}{l}\text { Fornecer uma perspectiva usada } \\
\text { para explicar a trajetória de um } \\
\text { estudo de caso eletrônico. }\end{array}$ \\
\hline $\begin{array}{l}\text { Dwivedi, YK; Wastell, } \\
\text { D; Laumer, S; } \\
\text { Henriksen, HZ; Myers, } \\
\text { MD; Bunker, D; } \\
\text { Elbanna, A; } \\
\text { Ravishankar, MN; } \\
\text { Srivastava, SC } \\
\end{array}$ & $\begin{array}{l}\text { Research on } \\
\text { information systems } \\
\text { failures and successes: } \\
\text { Status update and } \\
\text { future directions }\end{array}$ & 65 & 2015 & Revisão da literatura & Suporte & $\begin{array}{l}\text { Refletir sobre a necessidade de } \\
\text { novas perspectivas e orientações } \\
\text { de pesquisa, fornecendo insights } \\
\text { aos gerentes sobre fatores que } \\
\text { permitem o sucesso do sistema de } \\
\text { informação. }\end{array}$ \\
\hline $\begin{array}{l}\text { Ng, ST; Wong, YMW; } \\
\text { Wong, JMW }\end{array}$ & $\begin{array}{l}\text { Factors influencing the } \\
\text { success of PPP at } \\
\text { feasibility stage - A } \\
\text { tripartite comparison } \\
\text { study in Hong Kong }\end{array}$ & 60 & 2012 & Survey & Suporte político & $\begin{array}{l}\text { Explorar os principais } \\
\text { ingredientes de sucesso para } \\
\text { serem avaliados na fase inicial } \\
\text { dos projetos de parcerias público- } \\
\text { privadas }\end{array}$ \\
\hline
\end{tabular}




\begin{tabular}{|c|c|c|c|c|c|c|}
\hline Autor & Título & Citações & Ano & Método & FCS & Objetivo \\
\hline $\begin{array}{l}\text { Love, PED; Mistry, D; } \\
\text { Davis, PR }\end{array}$ & $\begin{array}{l}\text { Price Competitive } \\
\text { Alliance Projects: } \\
\text { Identification of } \\
\text { Success Factors for } \\
\text { Public Clients }\end{array}$ & 46 & 2010 & $\begin{array}{l}\text { Entrevista semi- } \\
\text { estruturada }\end{array}$ & Experiência & $\begin{array}{l}\text { Determinar fatores de sucesso } \\
\text { para alianças competitivas em } \\
\text { preços durante suas fases de } \\
\text { desenvolvimento de } \\
\text { relacionamento. }\end{array}$ \\
\hline $\begin{array}{l}\text { Tan, WG; Cater-Steel, } \\
\text { A; Toleman, M }\end{array}$ & $\begin{array}{l}\text { IMPLEMENTING IT } \\
\text { SERVICE } \\
\text { MANAGEMENT: A } \\
\text { CASE STUDY } \\
\text { FOCUSSING ON } \\
\text { CRITICAL SUCCESS } \\
\text { FACTORS }\end{array}$ & 45 & 2009 & Estudo de caso & $\begin{array}{l}\text { Comprometimento da } \\
\text { gestão }\end{array}$ & $\begin{array}{l}\text { Confirmar um conjunto de fatores } \\
\text { que contribuíram para o sucesso } \\
\text { do projeto. }\end{array}$ \\
\hline $\begin{array}{l}\text { Dey, PK; Kinch, J; } \\
\text { Ogunlana, SO }\end{array}$ & $\begin{array}{l}\text { Managing risk in } \\
\text { software development } \\
\text { projects: a case study }\end{array}$ & 40 & 2007 & Estudo de caso & Gestão de risco eficaz & $\begin{array}{l}\text { Desenvolver uma estrutura de } \\
\text { gerenciamento de risco para } \\
\text { projetos de desenvolvimento de } \\
\text { software na perspectiva dos } \\
\text { desenvolvedores. }\end{array}$ \\
\hline $\begin{array}{l}\text { Marek, T; Diallo, I; } \\
\text { Ndiaye, B; } \\
\text { Rakotosalama, J }\end{array}$ & $\begin{array}{l}\text { Successful contracting } \\
\text { of prevention services: } \\
\text { fighting malnutrition in } \\
\text { Senegal and } \\
\text { Madagascar }\end{array}$ & 39 & 1999 & Estudo de caso & $\begin{array}{l}\text { Gerenciamento de } \\
\text { contratos }\end{array}$ & $\begin{array}{l}\text { Expor bons exemplos para serem } \\
\text { replicados. }\end{array}$ \\
\hline Potnis, DD & $\begin{array}{l}\text { Measuring e- } \\
\text { Governance as an } \\
\text { innovation in the public } \\
\text { sector }\end{array}$ & 38 & 2010 & Revisão da literatura & $\begin{array}{l}\text { Estratégia adotada pela } \\
\text { gestão }\end{array}$ & $\begin{array}{l}\text { Avaliar as metodologias } \\
\text { existentes na ONU para avaliar a } \\
\text { governança eletrônica. }\end{array}$ \\
\hline $\begin{array}{l}\text { Arora, VK; Sarin, R; } \\
\text { Lonnroth, K }\end{array}$ & $\begin{array}{l}\text { Feasibility and } \\
\text { effectiveness of a } \\
\text { public-private mix } \\
\text { project for improved } \\
\text { TB control in Delhi, } \\
\text { India }\end{array}$ & 36 & 2003 & Survey & $\begin{array}{l}\text { Alcançar objetivo } \\
\text { desejado }\end{array}$ & $\begin{array}{l}\text { Avaliar a viabilidade de um } \\
\text { sistema público-privado para } \\
\text { melhorar o controle da } \\
\text { tuberculose. }\end{array}$ \\
\hline
\end{tabular}




\begin{tabular}{|c|c|c|c|c|c|c|}
\hline Autor & Título & Citações & Ano & Método & FCS & Objetivo \\
\hline $\begin{array}{l}\text { Hadjimichalis, C; } \\
\text { Hudson, R }\end{array}$ & $\begin{array}{l}\text { Rethinking local and } \\
\text { regional development - } \\
\text { Implications for radical } \\
\text { political practice in } \\
\text { Europe }\end{array}$ & 35 & 2007 & Estudo de caso & Ajuda da população & $\begin{array}{l}\text { Expor o que as pessoas realmente } \\
\text { fazem para construir progressivas } \\
\text { estratégias de desenvolvimento } \\
\text { local. }\end{array}$ \\
\hline $\begin{array}{l}\text { Liu, TT; Wang, Y; } \\
\text { Wilkinson, S }\end{array}$ & $\begin{array}{l}\text { Identifying critical } \\
\text { factors affecting the } \\
\text { effectiveness and } \\
\text { efficiency of tendering } \\
\text { processes in Public- } \\
\text { Private Partnerships } \\
\text { (PPPs): A comparative } \\
\text { analysis of Australia } \\
\text { and China }\end{array}$ & 33 & 2016 & $\begin{array}{l}\text { Revisão da literatura, } \\
\text { entrevista } \\
\text { semiestruturada e } \\
\text { survey }\end{array}$ & $\begin{array}{l}\text { Desempenho dos } \\
\text { processos de licitações }\end{array}$ & $\begin{array}{l}\text { Realizar uma análise comparativa } \\
\text { de fatores críticos que afetam as } \\
\text { parcerias público-privadas na } \\
\text { Austrália e na China. }\end{array}$ \\
\hline
\end{tabular}


Apesar da literatura apresentar diferentes FCS, como mostra a tabela 2, a fim de agrupar os FCS mais frequentemente apresentados nos artigos, de acordo com os quatro fatores apresentados por Shenhar, Dvir e
Levy (2001), elaborou-se a tabela 3. Como cada artigo tem sua particularidade no projeto abordado, os FCS foram separados nos quatro tipos propostos pelos autores.

Tabela 3 - Fatores Críticos de Sucesso segundo Shenhar, Dvir \&Levy (2001)

\begin{tabular}{|l|c|}
\hline \multicolumn{1}{|c|}{ FCS } & \# Publicações \\
\hline Preparação para o futuro & $39 \%$ \\
\hline Sucesso do negócio & $27 \%$ \\
\hline Eficiência do projeto & $23 \%$ \\
\hline Impacto no consumidor & $11 \%$ \\
\hline
\end{tabular}

Fonte: Autores.

Os FCS mais frequentes são: 'preparação para o futuro', que engloba os benefícios que o projeto trará (ou não) para a organização; e 'Sucesso do negócio', que só permite a sua avaliação posteriormente, com a mensuração das vendas do produto ou serviço (Shenrar, Dvir \& Levy, 2001). Em projetos públicos, os resultados dos projetos tendem a ser demorados, pois são projetos voltados para a sociedade, em sua maioria, de forma que a análise dos resultados não é rápida. Além de existir a dependência de outros stakeholders, a avaliação dos resultados obtidos com os projetos, sejam eles positivos ou não, nem sempre é de curto prazo. Isso justifica esses dois critérios aparecerem com maior frequência nos artigos da base.

A dimensão 'eficiência do projeto' é passível de avaliação somente no curto prazo, até que o projeto seja completado. Com o passar do tempo, sua importância relativa diminui. Já o fator 'impacto no consumidor' pode servir de base para a mensuração do sucesso a partir do momento em que o cliente começa a receber o produto do projeto (Shenrar, Dvir, Levy, \& Maltz, 2001).

Além disso, os fatores críticos de sucesso em projetos públicos não visam apenas o alcance do objetivo, mas fatores que influenciam no futuro da instituição e da sociedade, por exemplo, sustentabilidade e formas de financiamento.

\section{Considerações finais}

O objetivo desta pesquisa foi analisar a produção científica internacional que aborda o tema "sucesso em projetos públicos" e seus fatores críticos de sucesso, por meio da análise bibliométrica.

Em média, aproximadamente 9 artigos são publicados por ano, com destaque ao ano de 2018, que obteve maior número de publicações que o total de publicações nos 15 anos iniciais. 
Os Estados Unidos, China, Inglaterra e Austrália se destacam na produção, visto que juntos são responsáveis por aproximadamente 47\% de toda produção, na qual, 50 países participam. O Brasil, em quantidade de publicações, não chega a ser relevante, pois, com apenas dois artigos, não atinge nem $1 \%$ da amostra. Uma das publicações trata do processo de gestão territorial através da implementação e ancoragem de um projeto de investimento estrangeiro em um país emergente; a outra relata como as empresas estão introduzindo a sustentabilidade no gerenciamento de projetos, investigando também como essa iniciativa pode impactar no sucesso do projeto.

Ao tratar de instituições com maior quantidade de publicações, a China se destaca, pois possui três posições entre o ranking das 6 primeiras instituições abordadas. Ainda observando as organizações, é percebido o domínio da Ásia, pois, entre as 6 mais produtivas, 5 estão localizadas nesse continente.

A respeito dos fatores críticos de sucesso, foi utilizada a definição de Shenhar, Dvir e Levy (2001), no qual dividem os fatores em quatro: eficiência do projeto, sucesso do negócio, impacto no consumidor e preparação para o futuro, representando $23 \%, 27 \%, 11 \%$ e $39 \%$, respectivamente, o que torna mais fácil a compreensão e visualização do que os autores consideram FCS na base selecionada. Levando em consideração estas informações, os projetos associados ao setor público consideram como FCS, em sua maioria, não apenas aqueles voltados ao alcance do objetivo, mas também fatores que influenciam no futuro como, por exemplo, formas de financiamento, auxílio governamental e sustentabilidade.

Os FCS mais frequentes mostram que a avaliação do sucesso dos projetos públicos é futura, não imediata como em projetos do setor privado. Os projetos públicos têm características especificas como análise e aprovação da sociedade, dos investidores, o envolvimento de vários stakeholders e, muitas vezes, os projetos não visam lucro. Diante disso, a análise de sucesso é futura, posterior a sua entrega ou a utilização do produto ou serviço.

As contribuições pretendidas por esse trabalho são de auxiliar futuras pesquisas, caracterizando a produção científica sobre sucesso em projetos públicos e, apresentando os seus FCS, servir como base para os gerentes de projetos públicos que querem melhorar seus índices de sucesso em projetos.

Um fator limitante para este trabalho foi a análise reservada ao acervo disponível na base Web of Science. Portanto, novos horizontes podem ser explorados, analisando outras bases e fazendo estudos de caso em organizações do setor público, comparando o sucesso em projetos nessas organizações aos FCS encontrados na literatura.

\section{Referências}

Azimi, A., \& Manesh, F.S. (2012). A New Model to Identify and Evaluate Critical Success Factors in the IT Projects; Case Study: Using RFID Technology in "Iranian Fuel Distribution System". International 
Journal of Information Science and Management, 99-112.

Bressan, F. (2000). O método do estudo de caso. Administração online, v. 1, n. 1, p. 113.

British Standard Institute - BSI (2000). Guide to Project Management. BS 6079,. BSI, UK

Buchanan, J. (2008). Measuring up. PM Network. Project Management Institute.

Bullen, C. V. \& Rockart, J. F. (1981) A primer on critical success factors. Massachusetts: Center for Information Systems Research, Sloan School of Management, MIT, 69.

Chueke, G.V. \& Amatucci, M. (2015) O que é bibliometria? Uma introdução ao Fórum. Internext, 10 (2), 1-5.

Conde, M.V.F. \& Araújo-Jorge, T.C. (2003). Modelos e concepções de inovação: a transição de paradigmas, a reforma da C\&T brasileira e as concepções de gestores de uma instituição pública de pesquisa em saúde. Ciência \& Saúde Coletiva, Rio de Janeiro, 8 (3), 738-738, jan.

Cooper, R.G. \& Kleinschimidt, E. (1995). Benchmarking the firm's critical success factors in New Product Development. The Journal of Product Innovation Management, USA, 12(5), 374-391.

Da Costa, E.A. (2002). Gestão estratégica. Editora Saraiva, 2002.

De Farias Filho, J.R. \& Almeida, N.O. (2010). Definindo sucesso em projetos. Revista de Gestão e Projetos, 1(2), 68-85.

Duffy, M. (2006). Gestão de projetos. Elsevier Brasil.

Forster, N. \& Rockart, J. (1989). Critical Success Factors: An Annotated Bibliography. Working Paper no. 191. Center for Information Systems Research, Sloan School of Management. Massachusetts Institute of Technology. June 1989.

Franco, E. F., Hirama, K., \& Carvalho, M. M. (2018). Applying system dynamics approach in software and information system projects: A mapping study. Information and Software Technology, 93, 58-73. https://doi.org/10.1016/j.infsof.2017.08.013

Garcia, R. \& Calantone, R. (2002) A critical look at technological innovation typology and innovativeness terminology: a literature review. Journal of Product Innovation Management, USA, 19 (2) 110-132.
Hart, S. (1993). Dimensions of success in new product development: an exploratory investigation. Journal of Marketing Management, 9, 23-41.

Keeling, R. (2017). Gestão de projetos. Editora Saraiva.

Kerzner, H. (2010). Gestão de projetos: as melhores práticas. Porto Alegre: Bookman.

Kerzner, H. (2011). Gerenciamento de Projetos: uma abordagem sistêmica para planejamento, programação e controle. Editora Blucher.

Link, C. P., Silva, G., Barichello, R., Dal Magro, C. B. (2020). Fatores críticos no gerenciamento de projetos públicos sustentáveis. Revista de Gestão e Projetos, 11(2), 87-109, maio/ago.

Maccari, E.A \& Dos Santos Teixeira, G.C. (2014). Estratégia e planejamento de projeto para acompanhamento de alunos egressos de programas de pós-graduação strictosensu. Revista de Administração da Universidade Federal de Santa Maria, 7 (1) 101-116.

Patah, L.A. \& Carvalho, M.M. (2012). Métodos de gestão de projetos e sucesso dos projetos: um estudo quantitativo do relacionamento entre estes conceitos. Revista de Gestão e Projetos, [s.1.], 3 (2), 185-185, 1 ago. Universidade Nove de Julho. http://dx.doi.org/10.5585/gep.v3i2.94.

Pestana, C. V. S., \& Valente, G. V. P. (2010). Gerenciamento de projetos na administração pública: da implantação do escritório de projetos à gestão de portfólio na secretaria de estado de gestão e recursos humanos do Espírito Santo. In III Congresso Consad de gestão pública, Brasília, 2010. Disponível em:

http://www.repositorio.fjp.mg.gov.br/consad/ handle/123456789/232

Pinto, S.A.O. (2002) Gerenciamento de Projetos: Análise dos Fatores de Risco que Influenciam o Sucesso de Projetos de Sistemas de Informação. 2002. $235 \mathrm{f}$. Dissertação (Mestrado) - Curso de Administração, Dep. de Administração, Universidade de São Paulo, São Paulo, 2002. Poolton, J.\& Barclay, I. (1998). New Product Development From Past Research to Future Applications. Industrial Marketing Management, 27 (3), 197-212. 
Project Management Institute - PMI (2000). A Guide to the Project Management Body of Knowledge (PMBOK Guide). Project Management Institute.

Quintella, H.L.M.M., Rocha, H.M. \& Alves, M.F. (2005) Projetos de veículos automotores: fatores críticos de sucesso no lançamento. Rev. Produção, Rio de Janeiro, 15 (3), 335-335, dez.

Rabechini Junior, R. \& Carvalho, M.M. (2009). Gestão De Projetos Inovadores Em Uma Perspectiva Contingencial: Análise TeóricoConceitual E Proposição De Um Modelo. Revista de Administração e Inovação, São Paulo, 6 (3), 69-69, dez. 2009.

Russo, R. d., \& Silva, L. F. (2019). Critérios de sucesso e fatores de sucesso: é crítico distinguir o significado de ambos. Revista de Gestão e Projetos, 10(2), 1-5.

Shenhar, A., Dov Dvir, O. \& Levy, A.C.M. (2001); Project success: a multidimensional strategic concept., Long Range Planning, 34, 699-725

Shenhar, A. J., Dvir, D., Levy, O., \& Maltz, A. C. (2001). Project Success: a
Multidimensional Strategic Concept. Long

Range Planning, 34(6), 699-725.

https://doi.org/10.1002/em.20518

Shenhar, A. J.; Dvir, D. (2007). Reinventing project management: The diamond approach to successful growth and innovation. Boston: Harvard Business School Press.

Toledo, J.C., Silva, S.L., Mendes, G.H.S. \& Jugend, D. (2008). Fatores críticos de sucesso no gerenciamento de projetos de desenvolvimento de produto em empresas de base tecnológica de pequeno e médio porte. Gestão \& Produção, 15 (1), 117-134.

Turner, J.R. (1996). International Project Management Association global qualification, certification and accreditation. International Journal of Project Management, 14 (1), 1-6.

Vanti, N. A. P. (2002) Da bibliometria à webometria: uma exploração conceitual dos mecanismos utilizados para medir o registro da informação e a difusão do conhecimento. Ci. Inf, Brasília, 31(2), 152-162, ago. 